\title{
Seletividade de herbicidas para batata-doce
}

\section{Selectivity of herbicides to sweet potato}

\author{
Núbia M. Correia ${ }^{\text {** }}$, Agnaldo D. F. Carvalho ${ }^{b}$ \\ ${ }^{a}$ Centro de Pesquisa Avançado dos Cerrados, Empresa Brasileira de Pesquisa Agropecuária, Brasília, DF, Brasil. ${ }^{\mathrm{b}}$ Centro Nacional de Pesquisa \\ de Hortaliças, Empresa Brasileira de Pesquisa Agropecuária, Brasília, DF, Brasil.
}

Resumo: Introdução: Nas áreas maiores e de maior tecnificação do sistema de produção da batata-doce, as plantas daninhas são controladas com herbicidas. Contudo, existem apenas dois herbicidas registrados para a cultura no Brasil.

Objetivo: Estudar a seletividade de diferentes herbicidas para a cultura da batata-doce, em função do genótipo e da dosagem de cada produto.

Métodos: Dois experimentos foram desenvolvidos em condiçoes de campo, com as cultivares Canadense e Brazlândia Roxa, um para cada cultivar. O delineamento experimental foi o de blocos ao acaso, com 13 tratamentos e três repetições. Os tratamentos consistiram de seis herbicidas pulverizados em duas dosagens (clomazone 0,54 e 1,08 kg ha-1, flumioxazin 0,02 e 0,03 kg $\mathrm{ha}^{-1}$, linuron 0,72 e $0,99 \mathrm{~kg} \mathrm{ha}^{-1}$, metribuzin 0,36 e $0,48 \mathrm{~kg} \mathrm{ha}^{-1}$, oxadiazon 0,25 e $0,50 \mathrm{~kg} \mathrm{ha}^{-1}$ e sulfentrazone 0,25 e $0,50 \mathrm{~kg} \mathrm{ha}^{-1}$ ) e uma testemunha sem aplicação. Avaliações de fitointoxicação, população de plantas, comprimento da haste principal, produtividade de raízes tuberosas (descarte, comercial e total) e controle de plantas daninhas foram realizadas.

Resultados: A interação cultivares e tratamentos de herbicidas não foi significativa para nenhuma característica avaliada. Entre os herbicidas, sulfentrazone na maior dosagem foi o mais fitotóxico para batata-doce com notas de $40 \%$ a $44 \%$. Todavia, nenhum dos tratamentos de herbicida afetou negativamente a produtividade de raízes tuberosas.

Conclusões: As cultivares Canadense e Brazlândia Roxa possuem resposta semelhante aos herbicidas testados; e os herbicidas clomazone, flumioxazin, linuron, metribuzin e oxadiazon são promissores para uso na cultura da batata-doce.
Abstract: Background: In the largest areas and greater technification of the sweet potato production system, weeds are controlled with herbicides. However, there are only two herbicides registered for the crop in Brazil. Objective: The aim of this study was to evaluate the selectivity of different herbicides for the sweet potatoes crop, depending on the genotype and dosage of each product.

Methods: Two experiments were carried out under field conditions, with the Canadense and Brazlândia Roxa cultivars, one for each cultivar. The experimental design was a randomized block, with 13 treatments and three replications. The treatments consisted of six herbicides sprayed in two doses (clomazone 0.54 and $1.08 \mathrm{~kg} \mathrm{ha}^{-1}$, flumioxazin 0.02 and $0.03 \mathrm{~kg} \mathrm{ha}^{-1}$, linuron 0.72 and $0.99 \mathrm{~kg} \mathrm{ha}^{-1}$, metribuzin 0.36 and $0.48 \mathrm{~kg} \mathrm{ha}^{-1}$, oxadiazon 0.25 and $0.50 \mathrm{~kg} \mathrm{ha}^{-1}$ and sulfentrazone 0.25 and $0.50 \mathrm{~kg} \mathrm{ha}^{-1}$ ) and a control without application. Phytotoxicity assessments, plant population, main stem length, tuberous root productivity (discarded, commercial and total) and weed control were performed.

Results: The interaction of cultivars and herbicide treatments was not significant for any trait evaluated. Among the herbicides, sulfentrazone in the highest dose was the most phytotoxic for sweet potatoes with grades of $4.0 \%$ to $44 \%$. However, none of the herbicide treatments negatively affected the yield of tuberous roots.

Conclusions: The cultivars Canadense and Brazlândia Roxa have a similar response to the tested herbicides; and the herbicides clomazone, flumioxazin, linuron, metribuzin and oxadiazon are promising for use in sweet potato crop.

Keywords: chemical control, phytotoxicity, ipomoea batatas (L) Lam.

Palavras-chave: controle químico, fitointoxicação, ipomoea batatas (L) Lam.

\section{Introdução}

Journal Information:

ISSN: 2763-8332

Website: https://www.weedcontroljournal.org/ Jornal da Sociedade Brasileira da Ciência das Plantas Daninhas

Como citar: Correia NM, Carvalho ADF. Seletividade de herbicidas para batata-doce. Weed Control J. 202 1;20:e202100740.

https://doi.org/10.7824/wcj.2021;20:00740

\section{Aprovado por:}

Editor-Chefe: Daniel Valadão Silva

Editor Associado: Theodoro Scneider

Conflitos de interesse: Os autores declaram não haver conflito de interesses em relação à publicação deste manuscrito.

Recebido: Novembro 15, 2020

Aprovado: Abril 20, 2021

* Corresponding author:

<nubia.correia@embrapa.br>

\section{(c) (i)}

Este é um artigo de acesso aberto distribuído sob os termos da Licença de Atribuição Creative Commons, que permite o uso irrestrito, distribuição e reprodução em qualquer meio, desde que o autor original e a fonte sejam creditados.

Copyright: 2021
A batata-doce (Ipomoea batatas (L) Lam.) é uma das principais hortaliças cultivadas no Brasil. Destaca-se por ser um alimento versátil, muito apreciada pelos grupos que procuram alimentação mais saudável, principalmente, os praticantes de atividades físicas intensas. Em 2019, foram cultivados no Brasil mais de 57 mil hectares, com produção de 805 mil toneladas e produtividade média de 14 toneladas por hectare(IBGE, 2020). No entanto, apesar da sua rusticidade e facilidade de cultivo, essa hortaliça também é prejudicada pela interferência das plantas daninhas, que pode depreciar a quantidade e a qualidade das raízes, com perdas de produção de até 99,7 \% se o controle não for realizado (Harrison e Jackson, 2011; Cavalcante et al., 2017; Santos et al., 2018a; Santos et al., 2018b). Além da redução na quantidade e qualidade do produto colhido, as plantas daninhas podem servir como hospedeiras alternativas de pragas, doenças e nematoides (Braz et al., 2016; Bellé et al., 2017; Barbosa et al., 2020).

O manejo das plantas daninhas na cultura da batata-doce, por esses motivos, assume grande importância, cujo método de controle escolhido será em função do tamanho e da tecnificação da área. A diversidade das áreas de cultivo dessa hortaliça no Brasil é muito grande, pois engloba do pequeno ao grande produtor, distribuídos em diversas regiões produtoras do Sul ao Nordeste. Nas áreas maiores e de maior tecnificação do sistema de produção, as plantas daninhas são controladas com herbicidas, justificado pela escassez de mão-de-obra e custo mais elevado do controle mecânico, com capina. Contudo, existem apenas dois herbicidas registrados para a cultura da batata-doce no Brasil, o linuron e o clethodim. O primeiro deve ser aplicado no pré-plantio das mudas, em pré ou pós-emergência 
inicial das plantas daninhas, para o controle de espécies eudicotiledôneas (Rodrigues e Almeida, 2018). Já o clethodim é recomendado para aplicação em pós-emergência, inclusive da cultura, e controla exclusivamente espécies da família Poaceae (Rodrigues e Almeida, 2018). Portanto, há uma carência de herbicidas para o controle de plantas daninhas (mono e eudicotiledôneas) na cultura da batata-doce, tanto em pré como em pós-emergência.

Diversos herbicidas, como clomazone, flumioxazin e metribuzin foram considerados promissores para uso na cultura da batata-doce, dependendo da época de aplicação, dosagem e genótipo, com pouca ou nenhuma depreciação na produtividade de raízes (Freitas et al., 1994; Kelly et al., 2006; Beam et al., 2017; Santos et al., 2018a; Santos et al., 2018b; Wadl et al., 2020). Outros herbicidas com potencial de uso é o sulfentrazone e o oxadiazon, com base na resposta para tomate, batata e mandioca, para sulfentrazone (Scariot et al., 2013; Correia, 2015; Correia e Carvalho, 2019); ou registro para outras hortaliças, como cebola e alho, no caso de oxadiazon (Rodrigues e Almeida, 2018).

Estudos de seletividade são muito importantes para avaliar a ação fitotóxica de determinado herbicida para a cultura de interesse econômico. A seletividade é a base para o sucesso do controle químico de plantas daninhas na produção agrícola, sendo considerada como uma medida da resposta diferencial de diversas espécies de plantas a um determinado herbicida (Alterman e Jones, 2003). Quanto maior a diferença de tolerância entre a cultura e a planta daninha, maior a segurança de aplicação (Oliveira Jr. e Inoue, 2011). A seletividade depende de muitos fatores inter-relacionados e pode ser afetada pelo material genético, que resulta na tolerância diferencial de genótipos da mesma espécie. A esse respeito, foram observadas variações pouco expressivas entre genótipos de batata-doce para os herbicidas clomazone (Santos et al., 2018a; Wadl et al., 2020) e s-metolachlor (Meyers et al., 2012).

Mesmo sem registro do herbicida junto ao Ministério da Agricultura, Pecuária e Abastecimento - MAPA para controle de plantas daninhas na cultura de interesse, estudos de seletividade são importantes para avaliar herbicidas com potencial de uso e posterior registro, se houver interesse da indústria. Assim, objetivou-se estudar a seletividade de diferentes herbicidas para a cultura da batata-doce, em função do genótipo e da dosagem de cada produto, classificando-os como promissores ou não para uso na cultura.

\section{Material e Métodos}

Dois experimentos foram realizados em condições de campo, com as cultivares Canadense e Brazlândia Roxa, um para cada cultivar, no período de 15/01/2020 a 08/07/2020, na estação experimental da Embrapa Hortaliças, em Brasília, DF. A latitude, longitude e altitude do local é de $15^{\circ} 55^{\prime} 54,5$ ”S, $48^{\circ} 08^{\prime} 21^{\prime \prime} \mathrm{W}$ e $1002 \mathrm{~m}$, respectivamente. Segundo a classificação de Köppen-Geiger, o clima da região é do tipo Aw - tropical com inverso seco (Cardoso et al., 2014).

O solo da área experimental apresentou pH (em água) de 6,2; matéria orgânica de 35,5 $\mathrm{g} \mathrm{dm}^{-3}$; $\mathrm{P}$ (Mehlich) de

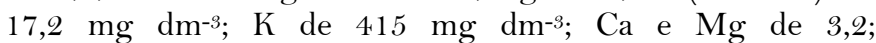
$0,9 \mathrm{cmol}_{\mathrm{c}} \mathrm{dm}^{-3}$, respectivamente; e B, Cu, Fe, Mn, Zn, S de 0,$16 ; 2,3 ; 51,2 ; 52,4 ; 9,6 ; 7,1 \mathrm{mg} \mathrm{dm}^{-3}$, respectivamente. Quanto à textura, o solo foi classificado como argiloso, com 507,437 e $56 \mathrm{~g} \mathrm{~kg}^{-1}$ de argila, silte e areia, respectivamente.

O solo foi preparado com gradagem seguida de subsolagem. Depois aração e gradagem, com posterior abubação a lanço manual de $1000 \mathrm{~kg} \mathrm{ha}{ }^{-1}$ do formulado 04-30-16 (NPK). Essas operações foram seguidas do encanteiramento, com enxada rotativa encanteiradora, para incorporação do adubo e formação das leiras. O plantio das mudas foi manual, em 16/01/2020, no espaçamento de $30 \mathrm{~cm}$ entre plantas $(80 \mathrm{~cm}$ entre fileiras), utilizando-se ramas do ponteiro com cerca de $30 \mathrm{~cm}$ de comprimento. As adubações de cobertura foram realizadas aos 42 e 62 dias após o plantio (DAP), com $75 \mathrm{~kg} \mathrm{ha}^{-1}$ do formulado 20-OO-20 (NPK) em cada época.

As parcelas foram constituídas de 2,4 m de largura (três linhas de batata-doce) e 3,5 m de comprimento, com a segunda linha da parcela (centro) com 2,1 m de comprimento como área útil, totalizando $1,68 \mathrm{~m}^{2}$.

Nos dois experimentos, o delineamento experimental foi o de blocos ao acaso, com 13 tratamentos e três repetições. Os tratamentos consistiram de seis herbicidas pulverizados em duas dosagens (clomazone 0,54 e $1,08 \mathrm{~kg} \mathrm{ha}^{-1}$, flumioxazin 0,02 e $0,03 \mathrm{~kg} \mathrm{ha-1}$, linuron 0,72 e $0,99 \mathrm{~kg} \mathrm{ha}^{-1}$, metribuzin 0,36 e $0,48 \mathrm{~kg} \mathrm{ha}^{-1}$, oxadiazon 0,25 e $0,50 \mathrm{~kg} \mathrm{ha}^{-1} \mathrm{e}$ sulfentrazone 0,25 e $0,50 \mathrm{~kg} \mathrm{ha}^{-1}$ ) e uma testemunha sem aplicação, mantida sem plantas daninhas com catação manual, durante o período de 30 dias após o plantio até a colheita. O nome do produto comercial, a formulação, a concentração e o fornecedor de cada herbicida estudado nos experimentos estão apresentados na Tabela 1.

Tabela 1. Nome do ingrediente ativo e do produto comercial, formulação, concentração e fornecedor dos herbicidas estudados nos experimentos.

\begin{tabular}{|c|c|c|c|c|}
\hline \multicolumn{2}{|c|}{ Herbicida } & \multirow{2}{*}{ Formulação $^{(1)}$} & \multirow{2}{*}{$\begin{array}{c}\text { Concentração } \\
\left(\mathrm{g} \mathrm{L}^{-1}\right)\end{array}$} & \multirow{2}{*}{ Fornecedor } \\
\hline Ingrediente ativo & Produto comercial & & & \\
\hline Clomazone & Gamit $360 \mathrm{CS}$ & $\mathrm{CS}$ & 360 & FMC \\
\hline Flumioxazin & Flumyzin $500 \mathrm{SC}$ & $\mathrm{SC}$ & 500 & Sumitomo \\
\hline Linuron & Afalon $450 \mathrm{SC}$ & $\mathrm{SC}$ & 450 & ADAMA \\
\hline Metribuzin & Sencor 480 & $\mathrm{SC}$ & 480 & Bayer \\
\hline Oxadiazon & Ronstar $250 \mathrm{BR}$ & $\mathrm{EC}$ & 250 & Bayer \\
\hline Sulfentrazone & Boral $500 \mathrm{SC}$ & $\mathrm{SC}$ & 500 & FMC \\
\hline
\end{tabular}

(1) CS - Suspensão de Cápsulas, SC- Suspensão Concentrada, EC - Concentrado Emulsionável.

Fonte: Rodrigues e Almeida (2018) 
Os herbicidas foram pulverizados no dia anterior ao plantio das ramas, na pré-emergência das plantas daninhas (Figura 1). No momento da aplicação, em 15/01/2020, de 07:45-09:35 horas, foram registrados $25,4{ }^{\circ} \mathrm{C}-26,4{ }^{\circ} \mathrm{C}$ de temperatura do ar; $22,5{ }^{\circ} \mathrm{C}-26,5{ }^{\circ} \mathrm{C}$ de temperatura do solo; $85 \%-71 \%$ de umidade relativa do ar; $50 \%$ de nebulosidade e $1,2 \mathrm{~km} \mathrm{ha}{ }^{-1}-6,0 \mathrm{~km} \mathrm{ha}^{-1}$. O solo estava seco, mas, no dia seguinte, houve irrigação por aspersão de $20 \mathrm{~mm}$ na área experimental; com chuva de $20,2 \mathrm{~mm} 48$ horas depois. As aplicações foram feitas com pulverizador costal, à pressão constante (mantida por $\mathrm{CO}_{2}$ comprimido) de $2,0 \mathrm{kgf} \mathrm{cm}^{-2}$, munido de barra com quatro pontas de pulverização de jato plano leque TTI 110015 , espaçados de 0,5 m, espaçados de 0,5 $\mathrm{m}$, calibrado para proporcionar um volume de aplicação $150 \mathrm{~L} \mathrm{ha}^{-1}$ (a)

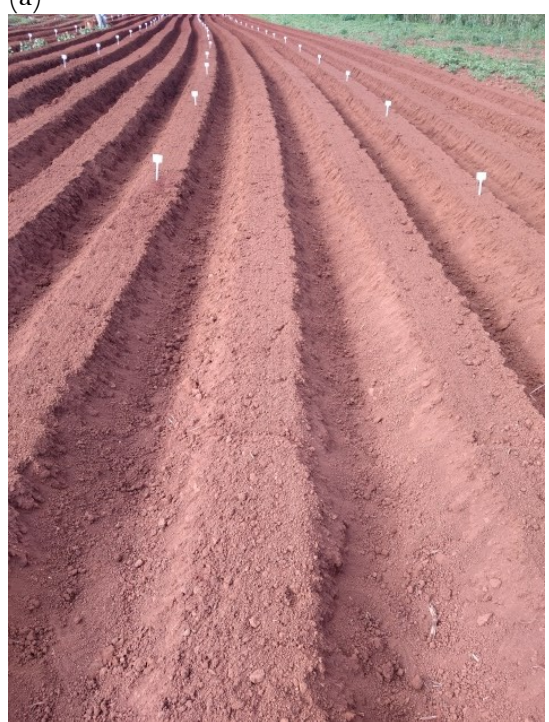

(b)

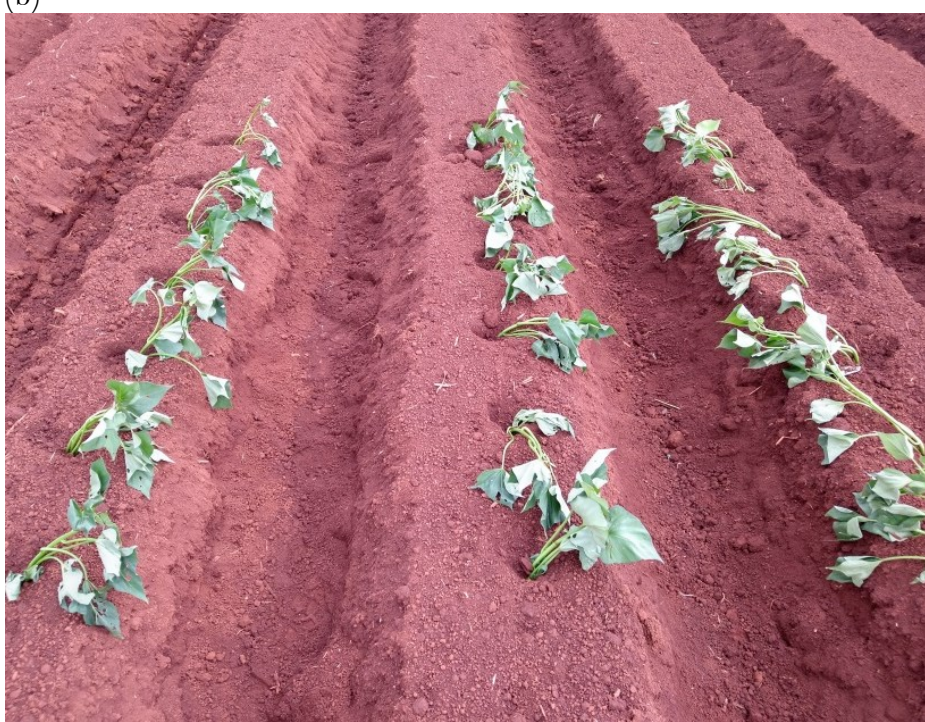

Figura 1. Área experimental antes (a) e após (b) o plantio das mudas de batata-doce, com a aplicação dos herbicidas antes do plantio e na préemergência das plantas daninhas.

Possíveis injúrias visuais nas plantas de batata-doce foram avaliadas aos 16, 22 e 30 dias após a aplicação (DAA) dos herbicidas, utilizando-se escala de notas de o a $100 \%$, em que zero representa a ausência de injúrias visuais e 100 a morte da planta (SBCPD, 1995). Nessas mesmas épocas também foi realizada a contagem de plantas na área útil das parcelas, e os dados estimados para população de plantas por hectare (mil plantas ha ${ }^{-1}$ ); e, aos 30 DAA, mediu-se o comprimento da haste principal, considerando a distância da sua base até a extremidade.

$\mathrm{O}$ controle de plantas daninhas foi avaliado aos $22 \mathrm{e}$ 30 DAA, com o auxílio de escala visual em porcentagem de acordo com SBCPD (1995). A partir da última avaliação todas as parcelas foram mantidas sem plantas daninhas, com a eliminação manual dos eventuais "escapes" do controle químico e a remoção manual de todas as plantas daninhas no tratamento sem herbicida (testemunha). As principais espécies de plantas daninhas da área experimental foram: Amaranthus retroflexus (caruru gigante), Commelina benghalensis (trapoeraba), Desmodium tortuosum (desmódio), Euphorbia heterophylla (leiteiro), Nicandra physaloides (joá-decapote), Oxalis latifolia (trevo azedo), Cyperus rotundus (tiririca) e Panicum maximum (capim-colonião)

Aos 174 dias após o plantio da batata-doce, as raízes tuberosas foram colhidas, com a retirada manual do solo. Posteriormente, estas foram separadas em comerciais e descarte, contabilizadas e pesadas, para a obtenção da quantidade e produção de raízes por parcela e da produção de raízes comerciais por planta. Os valores foram estimados para t ha ${ }^{-1}$ e mil unid. ha-1 ${ }^{-1}$ respectivamente para produtividade e quantidade de raízes comerciais e descarte. Raízes finas, pequenas e deformadas, com algum tipo de anomalia que pudesse estar associada ao uso de herbicidas, foram consideradas como descarte.

Os dados foram submetidos às pressuposições da análise de variância e os que não atenderam esses pressupostos foram transformados para $\sqrt{x+0,5}$. Em seguida, procedeu-se à análise de variância conjunta dos experimentos, por meio do programa estatístico SAS v. 8.2 (Muller e Fetterman, 2003). Os efeitos de cultivares e tratamentos de herbicidas (dosagens e testemunha) foram considerados fixos. Os efeitos das cultivares (experimentos), tratamentos de herbicidas e a interação destes, quando significativos, foram desdobrados e comparados pelo teste de comparação de médias de Tukey ao nível de significância de $5 \%$.

\section{Resultados e Discussão}

A interação cultivares e tratamentos de herbicidas não foi significativa para nenhuma característica avaliada, indicando independência entre os fatores, ou seja, as cultivares de batata-doce tiveram comportamento similar em relação aos herbicidas testados (Tabelas 2 e 3). Contrário ao observado por outros autores, que relataram variabilidade de resposta entre genótipos de batata-doce para os herbicidas (Meyers et al., 2012; Santos et al., 2018a, Santos et al., 2018b; 
Wadl et al., 2020), embora com diferenças pouco expressivas em alguns casos. A tolerância diferencial de genótipos de culturas a herbicidas pode ser explicada por variações morfológicas, fisiológicas ou bioquímicas, que afetam a capacidade de absorção, translocação e metabolização do herbicida pelas plantas (Oliveira Jr. e Inoue, 2011).

Tabela 2. Resultados do teste F da análise de variância para fitointoxicação aos 16, 22 e 30 dias após a aplicação (DAA) dos herbicidas, população de plantas por hectare aos 16, 22 e 30 DAA e controle de plantas daninhas aos 22 e 30 DAA, em função das cultivares de batatadoce e dos tratamentos de herbicidas.

\begin{tabular}{|c|c|c|c|c|c|c|c|c|}
\hline \multirow{2}{*}{ Fontes de variação } & \multicolumn{3}{|c|}{ Fitointoxicação - DAA } & \multicolumn{3}{|c|}{ População - DAA } & \multicolumn{2}{|c|}{ Controle - DAA } \\
\hline & 16 & 22 & 30 & 16 & 22 & 30 & 22 & 30 \\
\hline Cultivar & $19,21 * *$ & $30,38 * *$ & 16,17 *** & $12,20^{* * *}$ & $14,68^{* * *}$ & $10,13 * *$ & $7,48^{*} *$ & 0,37 \\
\hline Tratamento herbicida & 1,87 & $2,36^{*}$ & $3,16^{* * *}$ & 1,54 & 1,40 & 1,47 & $86,44^{* * *}$ & $57,66^{* * *}$ \\
\hline Cul. x Trat. herb. & 1,08 & 1,27 & 1,11 & 1,58 & 1,68 & 1,45 & 0,41 & 0,61 \\
\hline Bloco & 0,01 & 1,53 & 1,59 & 0,00 & 0,15 & 0,04 & 5,54 & $4,51^{*}$ \\
\hline $\mathrm{CV}(\%)$ & 55,03 & 45,66 & 61,21 & 9,28 & 8,20 & 10,10 & 7,76 & 9,55 \\
\hline \multirow{2}{*}{ Cultivar } & \multicolumn{8}{|c|}{ Valores médios } \\
\hline & \multicolumn{3}{|c|}{$\%$} & \multicolumn{3}{|c|}{ Plantas ha ${ }^{-1}$} & \multicolumn{2}{|c|}{$\%$} \\
\hline Brazlândia Roxa & $26,47 \mathrm{~b}^{(1)}$ & $29,74 \mathrm{~b}$ & 23,21 b & $35.409,04 \mathrm{~b}$ & $35.409,04 \mathrm{~b}$ & $34.951,16 \mathrm{~b}$ & 73,33 a & 63,94 a \\
\hline Canadense & $9,10 \mathrm{a}$ & 9,74 a & $8,21 \quad \mathrm{a}$ & $40.293,04 \mathrm{a}$ & $40.293,04 \mathrm{a}$ & $39.835,16 \mathrm{a}$ & $66,79 \mathrm{~b}$ & 62,82 a \\
\hline
\end{tabular}

*, *** Significativo aos níveis de $5 \%$ e $1 \%$ de probabilidade pelo teste $\mathrm{F}$ da análise de variância, respectivamente. (1) Médias seguidas da mesma letra, na coluna, não diferem significativamente entre si pelo teste de $\mathrm{F}$.

Tabela 3. Resultados do teste $\mathrm{F}$ da análise de variância para comprimento da haste principal aos 30 dias após a aplicação (DAA) dos herbicidas, produtividade e quantidade de raízes descarte, comercial e total (descarte + comercial) e produção de raízes comerciais por planta, em função das cultivares de batata-doce e dos tratamentos de herbicidas.

\begin{tabular}{|c|c|c|c|c|c|c|c|c|}
\hline \multirow{2}{*}{ Fontes de variação } & \multirow{2}{*}{ Comprimento } & \multicolumn{3}{|c|}{ Produtividade de raízes } & \multicolumn{3}{|c|}{ Quantidade de raízes } & \multirow{2}{*}{$\begin{array}{l}\text { Produção por } \\
\text { planta }\end{array}$} \\
\hline & & Descarte & Comercial & Total & Descarte & Comercial & Total & \\
\hline Cultivar & $38,41 * *$ & $40,38 * *$ & $25,59 * *$ & $32,40^{*} *$ & $62,68 * *$ & $78,92^{*} * *$ & $32,40^{* * *}$ & $18,14^{* * *}$ \\
\hline Tratamento herbicida & 1,38 & 1,56 & 0,29 & 0,34 & 1,94 & 1,22 & 0,34 & 0,16 \\
\hline Cul. x Trat. herb. & 0,55 & 0,28 & 0,29 & 0,23 & 0,21 & 0,41 & 0,23 & 0,54 \\
\hline Bloco & 0,70 & 0,06 & 2,82 & 2,21 & 0,30 & 2,34 & 2,21 & $3,54^{*}$ \\
\hline $\mathrm{CV}(\%)$ & 8,72 & 24,07 & 29,16 & 26,41 & 26,10 & 22,26 & 26,21 & 29,60 \\
\hline \multirow{2}{*}{ Cultivar } & \multicolumn{8}{|c|}{ Valores médios } \\
\hline & $\mathrm{cm}$ & & $\mathrm{t} \mathrm{ha}^{-1}$ & & & 1 unidades 1 & & $\mathrm{~g}$ \\
\hline Brazlândia Roxa & $33,57 \mathrm{~b}^{(1)}$ & $2,55 \mathrm{~b}$ & $15,76 \mathrm{~b}$ & $18,31 \mathrm{~b}$ & $38,34 \mathrm{~b}$ & $48,62 \mathrm{~b}$ & 86,96 b & $445,82 \mathrm{~b}$ \\
\hline Canadense & 42,84 a & 5,34 a & 26,95 a & 32,29 a & 95,20 a & 109,45 a & 204,65 a & 692,55 a \\
\hline DMS & 0,24 & 0,22 & 0,59 & 0,58 & 0,92 & 0,86 & 1,02 & 3,07 \\
\hline
\end{tabular}

米, ** Significativo aos níveis de 5\% e 1\% de probabilidade pelo teste $\mathrm{F}$ da análise de variância, respectivamente. (1) Médias seguidas da mesma letra, na coluna, não diferem significativamente entre si pelo teste de $\mathrm{F}$.

Quanto aos fatores isolados, as cultivares diferiram entre si para todas as variáveis estudadas, com exceção apenas para controle de plantas daninhas aos 30 DAA. Entretanto, as diferenças observadas entre as cultivares são justificadas por distinções naturais entre os materiais genéticos. A cultivar Canadense teve as menores notas de fitointoxicação, além das maiores médias de população de plantas, comprimento de ramos, produção de raízes comerciais por planta, produtividade e quantidade de raízes descarte, comercial e total (descarte + comercial) comparado a cultivar Brazlândia Roxa, que apresentou médias menores (Tabelas 2 e 3 ).

Para os tratamentos de herbicidas, houve diferença significativa entre eles somente para notas de fitointoxicação e controle de plantas daninhas. Aos 22 DAA, apenas a maior dosagem de sulfentrazone diferiu da testemunha sem aplicação e causou maior fitointoxicação na batata-doce, o mesmo ocorreu aos 30 DAA para as duas dosagens de sulfentrazone (Tabela 4). A fitointoxicação ocasionada pelo sulfentrazone, especialmente a maior dosagem, foi acentuada, com notas de $40 \%$ a $44 \%$. Mesmo assim, as plantas conseguiram se recuperar do efeito deletério do herbicida e produziram raízes tuberosas, sem prejuízos significativos.
Contudo, em um ambiente não favorável para essa recuperação, os decréscimos de produtividade de raízes seriam acentuados. Novos estudos são necessários para avaliar em outros ambientes, dosagens e cultivares a ação do sulfentrazone em batata-doce.

Na maioria dos casos, a tolerância ou susceptibilidade de uma planta aos herbicidas é variável de produto para produto (independentemente do mecanismo de ação e do grupo químico), e está associada à época de aplicação (pré ou pós-emergência), dosagem utilizada, tamanho da planta no momento da aplicação (para pós-emergência), características do solo e da planta (relacionadas à absorção, translocação e metabolização do herbicida, alteração no sítio de ação, etc.) (Oliveira Jr. e Inoue, 2011). Nesse sentido, flumioxazin, sulfentrazone e oxadiazon inibem a enzima protoporfirinogen oxidase (PPO), mas, são de grupos químicos diferentes, ftalimida, triazolona e oxadiazoles, respectivamente (Rodrigues e Almeida, 2018). Já o clomazone é do grupo químico isoxazolidinona e inibe a enzima 1-desoxi-d-xilulose 5-fosfato sintase (DOXPs) (Rodrigues e Almeida, 2018). Linuron e metribuzin são inibidores do fotossistema II e pertencem aos grupos químicos, derivado de ureia e triazinona, respectivamente (Rodrigues e Almeida, 2018). 
Tabela 4. Fitointoxicação aos 22 e 30 dias após a aplicação (DAA) dos herbicidas nas cultivares Canadense e Brazlândia Roxa (valores médios), além do controle de plantas daninhas aos 22 e 30 DAA, em função dos herbicidas estudados, pulverizados um dia antes do plantio da batata-doce, e da testemunha(1) sem aplicação.

\begin{tabular}{lccccc}
\hline \multirow{2}{*}{ Tratamentos } & \multirow{2}{*}{ Dosagem } & \multicolumn{2}{c}{ Fitointoxicação (\%) - DAA } & \multicolumn{2}{c}{ Controle (\%) - DAA } \\
\cline { 2 - 5 } 1. Clomazone & Menor & $10,00 \mathrm{ab}(2)$ & $3,33 \mathrm{ab}$ & $59,17 \mathrm{dc}$ & $59,17 \mathrm{c}$ \\
& Maior & $26,67 \mathrm{ab}$ & $23,33 \mathrm{abc}$ & $76,67 \mathrm{abc}$ & $70,00 \mathrm{abc}$ \\
2. Flumioxazin & Menor & $14,17 \mathrm{ab}$ & $9,17 \mathrm{abc}$ & $82,50 \mathrm{ab}$ & $67,50 \mathrm{abc}$ \\
& Maior & $11,67 \mathrm{ab}$ & $12,50 \mathrm{abc}$ & $86,67 \mathrm{ab}$ & $76,46 \mathrm{abc}$ \\
3. Linuron & Menor & $17,50 \mathrm{ab}$ & $13,33 \mathrm{abc}$ & $44,17 \mathrm{~d}$ & $36,67 \mathrm{~d}$ \\
& Maior & $16,67 \mathrm{ab}$ & $10,83 \mathrm{abc}$ & $66,67 \mathrm{bc}$ & $60,00 \mathrm{c}$ \\
4. Metribuzin & Menor & $15,00 \mathrm{ab}$ & $10,83 \mathrm{abc}$ & $70,83 \mathrm{bc}$ & $65,00 \mathrm{bc}$ \\
& Maior & $9,17 \mathrm{a}$ & $6,67 \mathrm{abc}$ & $74,17 \mathrm{abc}$ & $72,50 \mathrm{abc}$ \\
5. Oxadiazon & Menor & $21,67 \mathrm{ab}$ & $20,00 \mathrm{abc}$ & $75,83 \mathrm{abc}$ & $64,17 \mathrm{bc}$ \\
& Maior & $29,17 \mathrm{ab}$ & $25,00 \mathrm{abc}$ & $85,00 \mathrm{ab}$ & $73,75 \mathrm{abc}$ \\
6. Sulfentrazone & Menor & $27,50 \mathrm{ab}$ & $28,33 \mathrm{bc}$ & $94,17 \mathrm{a}$ & $87,50 \mathrm{ab}$ \\
7. Testemunha & Maior & $44,17 \mathrm{~b}$ & $40,83 \mathrm{c}$ & $95,00 \mathrm{a}$ & $91,25 \mathrm{a}$ \\
& - & $0,00 \mathrm{a}$ & $0,00 \mathrm{a}$ & $0,00 \mathrm{e}$ & $0,00 \mathrm{e}$ \\
\hline
\end{tabular}

(1) Testemunha sem aplicação de herbicida, com controle manual das plantas daninhas após 29 dias do plantio (aos 30 DAA). (2) Médias seguidas da mesma letra, na coluna, não diferem significativamente entre si pelo teste de Tukey a $5 \%$ de probabilidade.

Em relação ao controle de plantas daninhas, nas duas épocas de avaliação, o sulfentrazone, nas duas dosagens, resultou nas maiores porcentagens de controle de plantas daninhas, não diferindo de clomazone e metribuzin (nas maiores dosagens) e flumioxazin e oxadiazon (nas duas dosagens), aos 22 DAA; e de clomazone, metribuzin e oxadiazon (nas maiores dosagens) e flumioxazin (nas duas dosagens), aos 30 DAA. Nas duas dosagens estudadas, o linuron promoveu controle insatisfatório, menor que $70 \%$. Aliás, ao estabelecer o controle mínimo de $70 \%$ aos 30 DAA, os únicos tratamentos que obtiveram notas maiores ou iguais a esta foram as maiores dosagens de clomazone, flumioxazin, metribuzin e oxadiazon e as duas dosagens de sulfentrazone.

Esclarece-se que, a partir dos 30 DAA (equivalente a 29 dias do plantio) todas as plantas daninhas sobreviventes do controle químico foram eliminadas manualmente, para que

Referências

Alterman MK, Jones AP. Herbicidas: Fundamentos fisiológicos y bioquímicos del modo de acción. Ediciones Universidad Católica del Chile. 2003. 333 p.

Barbosa JPF, Silva JE da, Silva DJ da, Pinheiro RA, Leite R de A, Santana L dos S, Sousa TA de, Barros RP de. Registro da associação entre afídeos (Hemiptera: Aphididae) e plantas daninhas em cultivo orgânico e convencional de hortaliças. Revista Craibeiras de Agroecologia. 2020; 5(1): e9581 Disponível em: https://seer.ufal.br/index.php/era/article/ view/9581

Beam SC, Jennings KM, Monks DW, Schultheis JR, Chaudhari S. Influence of Herbicides on the Development of Internal Necrosis of Sweetpotato. Weed Technol. 2017; 31 (6):863-869. Disponível em: https://doi.org/10.1017/ wet.2017.60

Bellé C, Kulczynski SM, Kaspary TE, Kuhn PR. Weeds as alternative hosts to Meloidogyne incognita. Nematropica. 2017; 47(1): 26-33. Disponível em: https://www.cabi.org/isc/ a interferência destas na cultura fosse a menor possível, com base no período anterior a interferência, estabelecido na literatura como os primeiros 14, 17, 23 ou 24 dias após o plantio (Seem et al., 2003; Cavalcante et al., 2017). Todas as plantas daninhas da testemunha sem aplicação também foram eliminadas. Assim, a partir dos 29 dias do plantio todas as parcelas foram mantidas sem plantas daninhas.

\section{Conclusões}

As cultivares Canadense e Brazlândia Roxa possuem resposta semelhante aos herbicidas testados.

Os herbicidas clomazone, flumioxazin, linuron, metribuzin e oxadiazon são promissores para uso na cultura da batata-doce.

\section{FullTextPDF/2019/20193090067.pdf}

Braz GBP, Oliveira Jr. RS, Constantin J, Raimondi RT, Ribeiro LM, Gemelli A, Takano HK. Plantas daninhas como hospedeiras alternativas para Pratylenchus brachyurus. Summa Phytopathol. 2016; 42(3):233-238. Disponível em: https:// doi.org/10.1590/0100-5405/2129

Cardoso MR, Marcuzzo FF, Barros JR. Classificação climática de Köppen-Geiger para o estado de Goiás e Distrito Federal. Acta Geogr. 2014; 8(16):40-55. Disponível em: http://dx.doi.org/10.5654/acta.v8i16.1384

Cavalcante JT, Ferreira PV, Cunha JLXL, Silva Júnior AB, Silva MT, Carvalho IDE. Períodos de interferência de plantas daninhas em genótipos de batata-doce. Cult. Agron. 2017; 26(4):640-656. Disponível em: https:// doi.org/10.32929/2446-8355.2017v26n4p640-656

Correia NM. Levantamento fitossociológico de plantas daninhas em áreas de produção de tomate rasteiro dos 
estados de GO, MG e SP. Brasília, DF: Embrapa Hortaliças. 2015. 52p. (Documentos, 147). Disponível em: https:// ainfo.cnptia.embrapa.br/digital/bitstream/item/133449/1/ DOC-147X.pdf

Correia NM, Carvalho ADF. Seletividade de herbicidas para a cultura da batata. Hort. bras. 2019; 37(3):302-308. Disponível em: https://doi.org/10.1590/So102053620190308

Freitas $\mathrm{S}$ de $\mathrm{P}$, Silva JF da, Sediyama T, Ferreira LR. Controle químico de plantas daninhas na cultura da batatadoce (Ipomoea batatas (L.) Lam.). Rev. Ceres. 1994; 41(233):50 -56. Disponível em: http://www.ceres.ufv.br/ojs/index.php/ ceres/article/view/2056/103

Harrison Jr. HF, Jackson DM. Response of two sweet potato cultivars to weed interference. Crop Prot. 2011; 30(10):12911296, 2011. Disponível em: https://doi.org/10.1016/ j.cropro.2011.05.002

IBGE. Produção Agrícola Municipal 2017. Sistema IBGE de Recuperação Automática - SIDRA. Disponível em: https:// sidra.ibge.gov.br/tabela/5457\#resultado. Acesso em: 20 out. 2020.

Kelly ST, Shankle MW, Miller DK. Efficacy and tolerance of flumioxazin on sweetpotato (Ipomoea batatas). Weed Technol. 2006; 20(2):334-339. Disponível em: https:// doi.org/10.1614/WT-O4-330R1.1

Meyers SL, Jennings KM, Monks DW. Response of sweetpotato cultivars to s-metolachlor rate and application time. Weed Technol. 2012; 26(3):474-479. Disponível em: https://doi.org/10.1614/WT-D-11-00135.1

Muller KE, Fetterman BA. Regression and ANOVA: An Integrated Approach Using SAS Software. New York, NY, USA: John Wiley \& Sons, Inc., 2003. 592p.

Oliveira Jr. RS, Inoue, MH. 2011. Seletividade de herbicidas para culturas e plantas daninhas. In: Oliveira Jr. RS, Constantin J, Inoue, MH (Ed.). Biologia e manejo de plantas daninhas. Curitiba: Omnipax. 2011. p.243-262. Disponível em: http://omnipax.com.br/livros/2011/BMPD/BMPDlivro.pdf

Rodrigues BN, Almeida FLS. Guia de herbicidas. $7^{\mathrm{a}}$ ed., Londrina - PR: Edição dos autores, 2018. 764 p.

Santos EA dos, Andrade Júnior VC de, Viana DJS, Santos AA dos, Silva AJM da, Fialho CMT. Sensitivity of sweet potato genotypes to clomazone and weed interference. Rev. Caatinga. 2018a; 31(2):352-359. Disponível em: https:// doi.org/10.1590/1983-21252018v31n211rc

Santos EA dos, Andrade Júnior VC de, Sousa Júnior AS de, Okumura F, Simeone MLF, Santos JB dos, Azevedo AM. Selectivity of pre-emergent herbicides in sweet potato genotypes. Rev. Bras. Cienc. Agrar. 2018b; 13(1):e5511. Disponível em: https://doi.org/10.5039/agraria.v13i1a5511
SBCPD - Sociedade Brasileira da Ciência das Plantas Daninhas. Procedimentos para instalação, avaliação e análise de experimentos com herbicidas. Londrina. 1995. 42p.

Scariot CA, Costa NV da, Bosquese EP, Andrade DC de, Sontag DA. Seletividade e eficiência de herbicidas aplicados em pré-emergência na cultura da mandioca. Pesq. Agropec. Trop. 2013; 43(3):300-307. Disponível em: https:// doi.org/10.1590/S1983-40632013000300012

Seem JE, Creamer NG, Monks DW. Critical weed-free period for 'Beauregard' sweetpotato (Ipomoea batatas). Weed Technol. 2003; 17(4):686-695. Disponível em: https:// doi.org/10.1614/WTo2-089

Wadl PA, Cutulle MA, Jackson DM, Harrison HF. Evaluation of the USDA sweetpotato [Ipomoea batatas (L.) Lam.] germplasm collection for tolerance to the herbicide clomazone. Genet. Resour. Crop Evol. 2020; 67(5):11071113. Disponível em: https://doi.org/10.1007/s10722-02000921-8 